\title{
Entrepreneurial performance of the European Union - pivot of its economic security
}

\author{
Augustin IGNATOV*
}

DOI: $10.30682 / \mathrm{nm} 2002 \mathrm{~h}$

JEL codes: F43, F52, F63, O10, O52

\begin{abstract}
The goal of the present paper is to demonstrate whether the varying performance of the European Union states in terms of business and entrepreneurial attractiveness and activity is diminishing the level of overall economic security. Accordingly, the particular objectives which are to be achieved include: firstly, structuring the EU countries by performance groups in terms of economic efficiency; secondly, development of an innovative approach through which it can be analysed the dynamics and present level of economic security across the identified groups; and thirdly, analysis of interdependence between the selected indicators within the developed approach and, as result, suggestion of relevant policy measures at the level of the European Union. The methodology applied to reach the goal and objectives of the research includes a throughout quantitative analysis of data regarding the discrepancies in the European Union in terms of innovation output, resource productivity, employees' salary, business $R \& D$ expenditure, international investment positions, gross fixed capital formation, exports, energy efficiency and unemployment. The results reached expressively underline that the level of discrepancies among the performance groups in the European Union is high, these differences growing in the areas of business and entrepreneurial performance.
\end{abstract}

Keywords: Entrepreneurship, Economic security, European Union, Cohesion, Development.

\section{Introduction}

The present paper determines entrepreneurship and business performance as key elements of the economic security. The analysis concentrates on the member countries of the European Union assessing their present level of economic security and its dynamics. The community has met important challenges in the last decade considerably diminishing its role in the global economic and political affairs. This fact is generally reflected by decreasing share in the world's GDP as well as by the persistence of numerous unsolved problems related to social market economy and weakening business entrepreneurial efficiency. At the same time, the Union is con- fronting development disparities which considerably reduces the force of the single market as to act as the driver of economic progress. The weak central economic authorities in Brussels and the disputes among the member countries erode the growth potential and catching up capacities of the weaker economies. The only way the European Union is able to regain its pre-crisis economic positions in the global economy is by strengthening overall economic security of the community through reigniting business performance and entrepreneurship and reinsure that it is evenly distributed across the countries. As a result, both the weaker and wealthier European Union states will be in advantage since empow-

\footnotetext{
* University of Basel, Basel, Switzerland.

Corresponding author: augustin1ignatov1@gmail.com
} 
ering growth in the first inevitably leads to the progress of the second.

The goal of the present paper is to demonstrate whether the varying performance of the European Union states in terms of business and entrepreneurial attractiveness and activity is diminishing the level of overall economic security. Accordingly, the particular objectives which are to be achieved include: firstly, structuring the EU countries by performance groups in terms of economic efficiency; secondly, development of an innovative approach through which it can be analysed the dynamics and present level of economic security across the identified groups; and thirdly, analysis of interdependence between the selected indicators within the developed approach and, as result, suggestion of relevant policy measures at the level of the European Union. The methodology applied to reach the goal and objectives of the research includes a throughout quantitative analysis of raw data regarding the discrepancies in the European Union in terms of innovation output, resource productivity, employees' salary, business R\&D expenditure, international investment positions, gross fixed capital formation, exports, energy efficiency and unemployment. In order to exclude the possibility that these variables are associated due to coincidence, it was performed the Kaiser-Meyer-Olkin (KMO) test for identifying the sampling adequacy, and it was calculated the Bartlett's test of sphericity to assess whether the analysis performed is significant and the relationships identified are meaningful. Furthermore, quantitative analysis determines the Pearson's correlation coefficient between the selected indicators as well as the linear regressions analysis to find the existing relations and interdependence. The results reached expressively underline that the level of discrepancies among the performance groups in the European Union is high, these differences growing in the areas of business and entrepreneurial performance. The economic security of the European Union is, therefore, affected and the overall growth potential is diminished due to the persistence of this entrepreneurial heterogeneity.

The following recommendations are offered for European policy makers. First, the central authorities in the community, i.e. the Europe- an Parliament and the European Commission, should be delegated more responsibility in regulating the economic processes inside the single market as to increase the level of legislative and regulative congruence among the countries. This step is determinative as to offer a favourable background which will strengthen business and entrepreneurial efficiency. Second, developed nations of the European Union should contribute with investments to foster the economic capacities of weaker partners.

\section{Literature review}

The research subject related to economic convergence in the European Union has attracted much attention in the academic environment, many interesting ideas being promoted by various economists. According to Borsi \& Metiu (2015) the factors which affect the level of economic opportunities inside the country include: size of the local market, connectivity and the existing competition. Goecke \& Hüther (2016) mentioned about connectivity that it is one of few directions which can be directly improved by government, key areas in this regard being infrastructure and communications rehabilitation. Lopez-Bazo (2017) concluded that the more the region is accessible the higher is the probability that it will be chosen by the business to develop entrepreneurial activities. The potential of regions to growth is decided by their supply capacities i.e. resources and labour as well as cost benefits and economies of scale (Siljak, 2015). The main task of government is to foster the capacity of the region to access the wider market (Slomp, (2017). The main advantage which economies presently have as compared to the past is technology. It allows to bolster growth through improving economic dynamics by adopting "already existing technologies". The strategic task of governments in this regard is to assure stability and efficiency of the market (Salvatore, 2018, and Belostecinic et al., 2011). It is evident that there exists a stringent regional core-periphery stagnation, the countries failing to catch up, hence, there is "persistence and immobility" in reducing economic gaps which reduce overall growth potential (Quah, 1996). Yet, 
the technological diffusion, if properly directed, may lead to consistent spatial spillovers and, therefore, improve the regional convergence. In this regard, implementation of technology into the existing economic context becomes equally important as technology itself (Paci \& Pigliaru, 2002). At the level of the European Union, efficiency of technology application is diminished by the market "architecture" which two strategic weaknesses which diminish the growth potential of the community as a whole and namely relative low level of integration of product and labour markets "our product markets are less integrated and our labour is less mobile" (Combes \& Overman, 2004).

It can be underlined that the key aspect of improving convergence between the European macro-regions is related to mobilising the economic capacity and integrating smaller regions within the economic networks of the single market (Völlmecke et al., 2016). This direction will provide an immense growth potential for the Union as a whole increasing its economic positions on the global arena, therefore, fostering overall economic security (Dall'Erba \& Fang, 2017). The main policy target should be directed towards improving the regional operating environment for the local business which is the main agent capable of effectively integrating regional supply potential within the wider consumption network (Andersen et al., 2018). Certainly, European convergence policies proved to raise the income level of the European economically deprived countries (Forte et al., 2015 and Dimitrios et al., 2016). Nevertheless, this effect is rather limited, the fact being proved by relatively sizeable discrepancies in terms of income as well as those existing in advanced areas such as business innovation, research and development activities, export complexity, employment quality, and investment attractiveness (Ignatov, 2018). Thus, the development discrepancies inside the European Union undermine its long run level of economic security through diminishing the economic growth potential of the community (Ignatov, 2019).

The positions of the European Union as a global player are weakened not so much by internal development discrepancies as they are undermined by varying institutional efficiency. Accordingly, Magone (2017) and Chen (2016) remarked that the role of the European Union in the world's architecture is much less prominent as compared to economic superpowers i.e. the USA and China, the EU is viewed as a dispersed region with weak centralised power. Similarly, Szymańska \& Zalewska (2018) determined that the divergences are reducing the potential of the EU to efficiently promote key common interests such as economic security. Guild et al. (2016) concluded that economic security decreased qualitatively, since the Union comprises countries with varying economic dynamics, yet, had to gain quantitatively from larger country coverage. At the same time, Bieling et al. (2016) and Hallerberg et al. (2018) and Koenig \& Walter-Franke (2017) mentioned that, in the conditions of globalisation, the European Union should reframe its policy framework strengthening the rigour of central economic authorities.

The consolidation of the European economic security should start with strengthening economic governance which would introduce more balanced economic policies and more efficient implementation on the whole territory of the community (Dragneva \& Wolczuk, 2015). This situation would reinforce convergence in the European Union through creating a more symmetric business environment (Arvanitidis et al., 2016) and, as a result, it will be reignited cross country business activity (Anagnostou et al. 2016). The European Union needs to overcome regional isolationism by fostering inter-country cross border connectivity, thus, development would comprise a wider coverage and welfare growth would touch larger and smaller communities (Rodríguez-Pose \& Tselios, 2015). One of the potential benefits in these conditions is linked to quantitative and qualitative growth of entrepreneurial opportunities which would be evenly distributed across the territory of the Union (Loewen \& Schulz, 2019). Strong business sector is an essential precondition of enhanced economic security since it is responsible for future growth potential and competitiveness (Ignatov, 2018).

Consolidation of the business environment would benefit the innovation performance of 
the European Union since entrepreneurs would have more initiative arising from a more competitive environment (Blanco et al., 2018 and Kijek \& Matras-Bolibok, 2018). In the present policy environment, growth and competitiveness is unevenly distributed being concentrated in the North and West of the EU, while the South and East remain a space of missed opportunities. Theoretically, economic development of these regions would provide immense growth potential for the whole Union, consistently being accelerated trade and value exchange (Ciocanel \& Pavelescu, 2015). Due to weak development of them, the wealthier regions in the West and North reach development ceilings, being limited by weaker economic positions of the East and South (Potužáková \& Öhm, 2018 and Okólski, 2017). Therefore, it is the common interest to overcome discrepancies (Vella, 2015). In these conditions, the economic potential of the community will be empowered by the growth of the deprived regions opening more business opportunities for the West and North in the East and South, and vice-versa (Pegkas, 2015 and Ćetković \& Buzogány, 2016).

Accordingly, the present paper has the following research hypothesis and namely: discrepancies in terms of entrepreneurial performance between the countries of the European Union reduce the level of economic security and growth potential of the community.

\section{Methodology}

The present research is based on a comprehensive quantitative analysis of the indicators related to entrepreneurial performance. First step of it includes a throughout assessment of the raw data. This analysis is aimed to determine in depth the extent to which the countries of the European Union are affected by the development discrepancies. In order to optimise data presentation, it has been decided to structure the countries of the European Union into macro-regions or country clusters comprising states with similar economic development level and entrepreneurial performance. Thus, the first macro-region of the community i.e. the Benelux States (BNL) includes the following nations and namely: Belgium, Netherlands and Luxembourg. The second group, the Baltic States (TBS), comprises Estonia, Lithuania and Latvia, while the third group, the Scandinavian States, is formed of Sweden, Denmark and Finland. The fourth macro-region is one of the largest and includes all countries of the Mediterranean region (TMS) i.e. Spain, Greece, Croatia, Cyprus, Malta, Portugal, Slovenia and Italy. The fifth country cluster includes the states of the Visegrad group (TVS) i.e. Poland, the Czech Republic, Slovakia, and Hungary. The sixth macro-region of the community is the South East European region (TSEEC) which comprise Romania and Bulgaria. The seventh country cluster, the economic core of the Union, includes Germany, France, Austria and Ireland, it is the Western European region (TWEC). Further, there are presented the indicators which have been selected to identify the connectivity between varying entrepreneurial performance and economic security, the covered period is 2000-2017, or depending on availability. Firstly, it is analysed the discrepancies in terms of per millions of citizens' patent applications to the EPO by group of countries in the EU. Through this indicator, it can be identified where the innovation output potential is concentrated and which regions have higher performances. Also, it will be considered the dynamics and concluded whether there are any improvements in the distribution of innovation output during the researched period. Innovation output reflects the strength of the business sector in assuring the economy with new technologies, this dimension being strategic for the economic security since the potential technologic superiority is a key component of competitive advantages for the nations. The second indicator which is analysed is the discrepancies in terms of per $\mathrm{kg}$ resource productivity by group of countries in the EU. Productivity shows the present economic competitiveness of the countries, more productive nations having comparative advantages being able to compete for the markets more efficiently. Productivity of countries is a strategic component of economic security since it shows the overall economic efficiency within the economy. The third indicator is the discrepancies in terms of per employee' salary by group of countries in 
the EU. This factor is determinative for the European Union's economic security, it determining migration flows from less developed regions to wealthier ones, depopulation of countries being a serious threat to the future growth potential and reduction of development differences. It also affects the entrepreneurial performance, low income of the majority population being a factor reducing the business performance. The fourth indicator characterising entrepreneurial performance by regions is discrepancies in terms of per capita business $R \& D$ expenditure by group of countries in the EU. It shows the variations in terms of the business sector strength within the European Union. The more the business invests in research and development the higher is the probability that it will increase the quality of its activity and, therefore, gain from additional competitive advantages in terms of new (or improved) products, processes and services. Another important indicator which has been analysed by the present paper is international investment positions of the European Union's states, percentage of gross domestic product (GDP). This variable describes the differences between the countries' external financial assets and liabilities. Depending on this level, the country could be creditor, in case of positive balance, and debtor in the vice versa case. The next indicator which is analysed reflect the discrepancies in terms of per capita gross fixed capital formation per capita by group of countries in the EU. Capital formation is an important indicator of economic security determining the speed of growth of economies, improvement of productivity and melioration of living standards. The higher is the level of capital formation in the economy the stronger would be its development potential. The seventh indicator which is analysed regard the discrepancies in terms of per capita exports by group of countries in the EU. Exports per capita are determinative in showing the level of states' direct competitiveness as reported to other nations. High levels of exports per capita are signals of well-functioning economy, it being able to compete in an international environment. The business environment and entrepreneurs are relatively strong being able to find foreign markets and efficiently cover them. The eighth indi- cator considers the discrepancies in terms of per kilogram of oil equivalent energy efficiency by group of countries in the EU. Energy efficiency is highly important for an economy, it showing the extent to which energy consumption is optimised. Nevertheless, energy efficiency may be an indicator reflecting restrictive government pricing policies in the respective field, in this case, business sector tends to limit its activities and optimise expenses, situation which is not always favourable for the development of the private sector. The last indicator, but not the least, is unemployment, percentage of active population. It is a key component of states' economic security, high levels marking inconsistency of policies (for instance, too much social orientation motivating population to rather stay home and get unemployment benefits rather than joining the labour market, even if the salaries may not satisfy) and weak economic stability. At the same time, there are calculated the Pearson's correlation coefficients between the selected indicators. This analysis will make it possible to determine the linear association between indicators. Moreover, it is performed a linear regression analysis between the selected indicators to find the existing interdependence between the indicators. Accordingly, it will be possible to determine how the variables interact and how these are related, important observations to establish relevant conclusions. In order to exclude the possibility that these variables are associated due to coincidence, it was performed the Kaiser-Meyer-Olkin (KMO) Test for sampling adequacy. Afterwards, it was calculated the Bartlett's test of sphericity, therefore, it could be concluded whether the analysis performed is significant and the relationships identified are meaningful. On overall, the analysis of the raw data and regressions should offer a clear picture of the interdependence between entrepreneurial performance, growth potential and economic security.

\section{Results}

The present paper structures the countries of the European Union into seven groups which comprise states with similar development level and regional localisation. Accordingly, each 
group forms a European macro-region or states cluster, the characteristics of which are presented in Table 1. The first macro-region, i.e. the Benelux states (BNL), includes Belgium, Netherlands and Luxembourg, the second concentrates on the Baltic States (TBS) covering Estonia, Lithuania and Latvia. The third states-cluster regards the Scandinavian States (TSS) encompassing Sweden, Denmark and Finland. The fourth group, the Mediterranean States (TMS), is the largest in terms of the number of countries as it comprises Italy, Greece, Spain, Croatia, Cyprus, Malta, Portugal and Slovenia. The fifth states cluster covers the Visegrad Group countries (TVC) and includes Poland, the Czech Republic, Slovakia and Hungary. Romania and Bulgaria form the South East European macro-region of the community (TSEEC). The largest economic macro-cluster in the EU, which serves also as the economic core of community, includes the Western European countries (TWEC) i.e. Germany, France, Austria and Ireland. Table 1 presents the general characteristics of the macro-clusters in terms of population, GDP, and GDP per capita, considering dynamics. It is important to point out that the United Kingdom was not considered in this paper due to the fact that it is presently in the full process of leaving the community. As it was previously mentioned, the Western European cluster is the economic core of the EU since it concentrates $47.76 \%$ of GDP while holding only $36.62 \%$ of the population. This macro-region is followed by the Mediterranean states which produce $25.82 \%$ of the EU's GDP and concentrating $30.42 \%$ of the population. The smallest groups both in terms of population and sheer economic size are the Baltic States, the South East European countries. During the period of 2000-2018, the European GDP has increased with $71.3 \%$, the most modest growth being remarked in the Mediterranean cluster, while the most pronounced increase being characteristic for the South East European states. Economic development in the community favourably affected the level of prosperity of European citizens since the GDP per capita in the EU has increased with $64.5 \%$ during the researched period, the lowest growth being in TMS group, while the highest being characteristic for TSEEC and TBS. Despite of noticeable economic devel- opment in TBS, TSEEC and TVC, the population size has considerably declined or stagnated, thus, the potential for the future development being diminished. Okólski (2017) underlined that the population decline in the Eastern Europe is a direct consequence of massive emigration which is powered by considerable income differences between the Western and Eastern European Union. As it can be remarked in Table 1, the Scandinavian States, Benelux and the Western European countries have income levels much more superior as compared to the rest of country groups, the situation which reduces the general growth potential. According to Ignatov (2018), the income discrepancies are even more pronounced if considering the development gap between regions which have weakly been reduced in the conditions of underdeveloped infrastructure. Development discrepancies is presently one of the main challenges of the European Union diminishing overall competitiveness. This situation determines incongruity of the single market leading to gaps in the business performance all across the Union. Thus, companies in the North and West will find it easier to expand their activities in the South and East, while the firms originating from the less developed EU macro-regions will find it difficult to enter the markets of the Northern and Western EU states. At the first glance, many will conclude that the companies from the wealthier countries are in advantage, nevertheless, the extent of their success in the weaker macro-regions is minimised by: firstly, lower income levels, and secondly, feeble competition, factors leading to less intensive growth. In other words, less competitive and wealthy business environment impose modest growth ceilings limiting the abilities of the private sector to progress.

The innovation performance of the macro-regions in the European Union is varying. The leading states cluster in this regard is the Scandinavian region, followed by the Western European and Benelux countries. The least advanced innovation driven regions in the EU are the TSEEC, TBS, TVC and TMS. It can be noticed that the innovation output gap is considerable, TSEEC group making only $1.85 \%$ of leader's performance, the discrepancies consistently increasing in dynamics. This situation highlights the idea that the busi- 
Table 1 - Description of the European Union by group of countries.

\begin{tabular}{|l|c|c|c|c|c|c|c|c|}
\hline & $E U$ & $B N L$ & $T B S$ & $T S S$ & $T M S$ & $T V C$ & TSEEC & TWEC \\
\hline Pop. 2000 (million) & 428.47 & 26.54 & 7.30 & 19.36 & 125.98 & 64.16 & 30.65 & 154.49 \\
\hline Share 2000 & $100 \%$ & $6.19 \%$ & $1.70 \%$ & $4.52 \%$ & $29.40 \%$ & $14.97 \%$ & $7.15 \%$ & $36.06 \%$ \\
\hline Pop. 2018 (million) & 446.11 & 29.18 & 6.06 & 21.41 & 135.69 & 63.81 & 26.58 & 163.37 \\
\hline Share 2018 & $100 \%$ & $6.54 \%$ & $1.36 \%$ & $4.80 \%$ & $30.42 \%$ & $14.30 \%$ & $5.96 \%$ & $36.62 \%$ \\
\hline Diff. (abs) & 17.63 & 2.65 & -1.23 & 2.05 & 9.70 & -0.35 & -4.07 & 8.88 \\
\hline Dynamics & $3.95 \%$ & $9.06 \%$ & $-20.3 \%$ & $9.58 \%$ & $7.15 \%$ & $-0.55 \%$ & $-15.3 \%$ & $5.44 \%$ \\
\hline Change in share & $0.00 \%$ & $0.35 \%$ & $-0.34 \%$ & $0.28 \%$ & $1.01 \%$ & $-0.67 \%$ & $-1.19 \%$ & $0.57 \%$ \\
\hline GDP 2000 (trillion EUR) & 7.874 & 0.733 & 0.027 & 0.597 & 2.218 & 0.327 & 0.055 & 3.917 \\
\hline Share 2000 & $100 \%$ & $9.31 \%$ & $0.35 \%$ & $7.58 \%$ & $28.17 \%$ & $4.15 \%$ & $0.70 \%$ & $49.75 \%$ \\
\hline GDP 2018 (trillion EUR) & 13.483 & 1.283 & 0.100 & 0.998 & 3.482 & 0.925 & 0.258 & 6.440 \\
\hline Share 2018 & $100 \%$ & $9.51 \%$ & $0.74 \%$ & $7.40 \%$ & $25.82 \%$ & $6.86 \%$ & $1.91 \%$ & $47.76 \%$ \\
\hline Diff. (abs) & 5.610 & 0.549 & 0.073 & 0.402 & 1.264 & 0.599 & 0.203 & 2.522 \\
\hline Dynamics & $71.3 \%$ & $74.93 \%$ & $267.7 \%$ & $67.34 \%$ & $57.01 \%$ & $183.1 \%$ & $370.1 \%$ & $64.40 \%$ \\
\hline Change in share & $0.00 \%$ & $0.20 \%$ & $0.40 \%$ & $-0.17 \%$ & $-2.34 \%$ & $2.71 \%$ & $1.22 \%$ & $-1.99 \%$ \\
\hline GDP/cap 2000 (thds.) & 18376 & 27634 & 3738 & 30808 & 17603 & 5095 & 1791 & 25355 \\
\hline GDP/cap 2018 (thds.) & 30225 & 43957 & 16544 & 46613 & 25662 & 14503 & 9709 & 39417 \\
\hline$\%$ of the EU 2000 & $100 \%$ & $150.4 \%$ & $20.34 \%$ & $167.7 \%$ & $95.79 \%$ & $27.73 \%$ & $9.75 \%$ & $138 \%$ \\
\hline \% of the EU 2018 & $100 \%$ & $145.4 \%$ & $54.74 \%$ & $154.2 \%$ & $84.90 \%$ & $47.98 \%$ & $32.12 \%$ & $130.4 \%$ \\
\hline Growth & $64.5 \%$ & $59.1 \%$ & $342.5 \%$ & $51.3 \%$ & $45.8 \%$ & $184.7 \%$ & $442 \%$ & $55.5 \%$ \\
\hline
\end{tabular}

Source: Eurostat.

ness sector in the Scandinavian region is much more competitive as compared to the rest of countries since it generates a higher rate of innovation outputs. The Southern and Eastern parts of the EU face stagnation in terms of business performance, their results being modest over the researched period. Thus, the regions encompassing $52.04 \%$ of the population are affected by serious challenges in terms of generating innovation the fact which minimises overall competitiveness level of the EU. The economic "core" of the community i.e. the Western cluster and Benelux states, also, confront with serious challenges in terms of innovation output, especially, in the post crisis period, since the gap between these countries and the leading group is increasing.

The resource productivity differences among the EU country groups are also consistent, the

Figure 1 - Discrepancies in terms of per million of citizens patent applications to the EPO by group of countries in the EU.

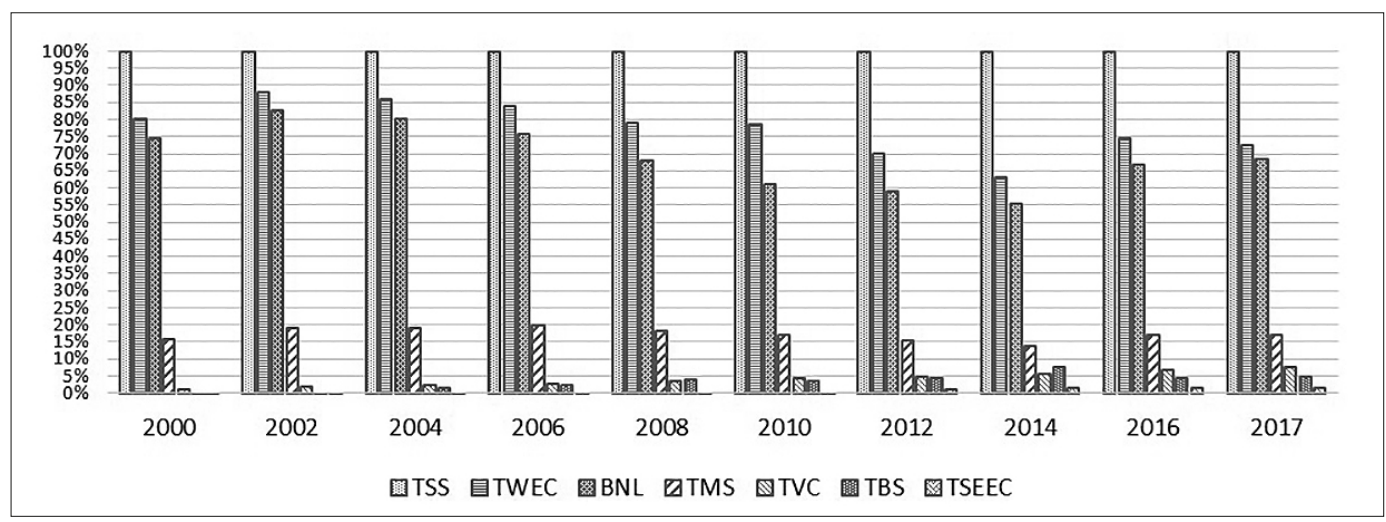

Source: Eurostat, indicator's code [pat_ep_ntot]. 
Figure 2 - Discrepancies in terms of per kg resource productivity by group of countries in the EU.

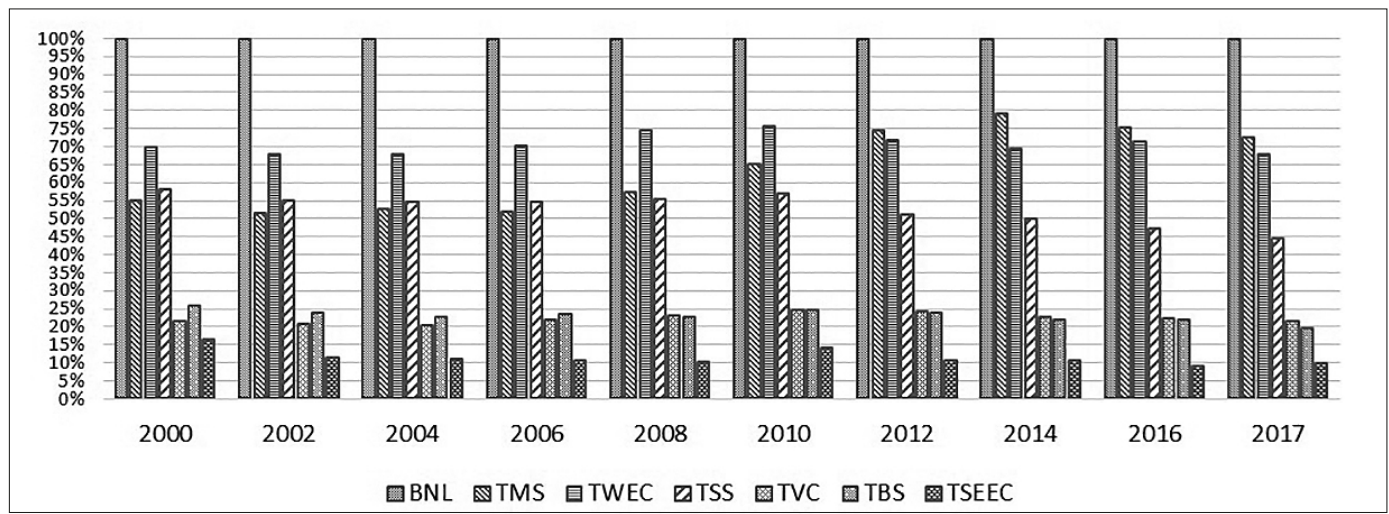

Source: Eurostat, indicator's code [t2020_rl100].

Figure 3 - Discrepancies in terms of per employee' salary by group of countries in the EU.

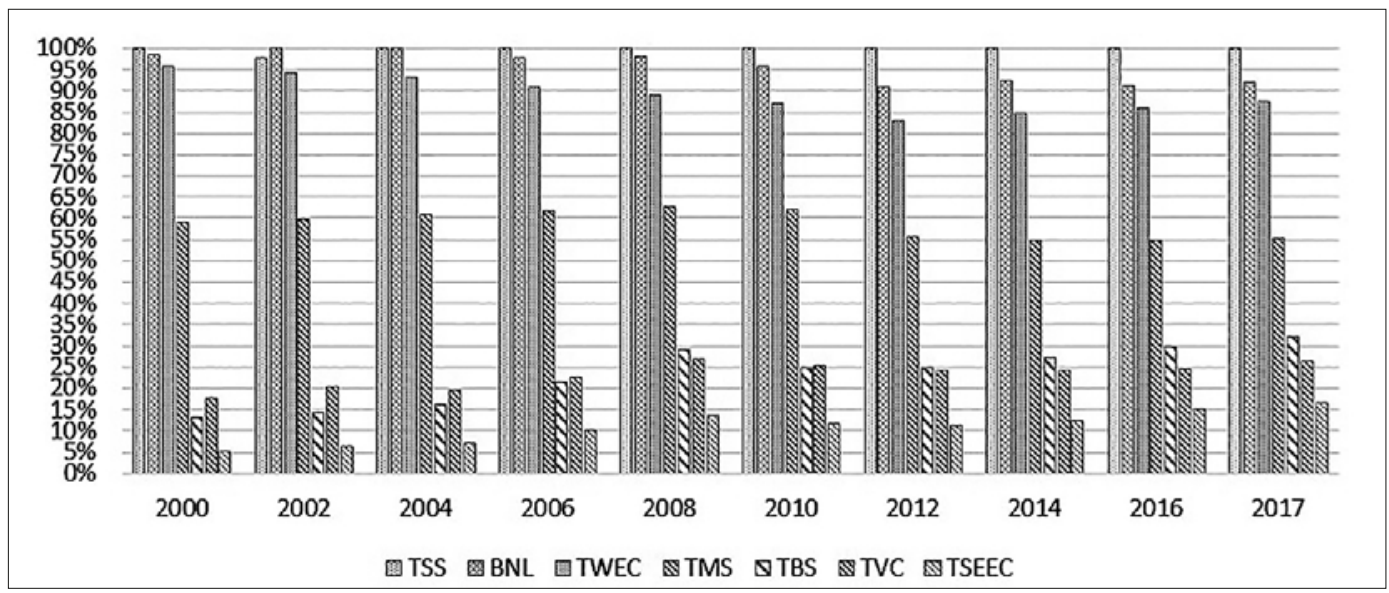

Source: Eurostat, indicators' codes [nama_10_gdp] and [nama_10_a10_e].

leading cluster in this regard is Benelux, followed by Mediterranean and Western European countries. The Scandinavian States register more modest performance as compared to innovation, their resource productivity making only $44.85 \%$ as compared to Benelux. The least advanced region in this regard is the South East whose resource productivity makes only $10.85 \%$. The Baltic States and the Visegrad countries also register modest performances which range about $20 \%$. The gaps tend to persist in dynamics, the least competitive clusters in this regard, practically, have not increased their results as compared to the leading groups.

The differences in terms of salaries across the macro-regions of the European Union are size- able. The highest levels of employees' remuneration are characteristic for the Scandinavian States, followed by Benelux and the Western European countries. The lowest levels of remuneration are characteristic for the South East European region followed by the Visegrad group countries and the Baltic States. The performance of the Mediterranean countries is somewhere in the middle. It should be mentioned that the situation has weakly improved over the researched period, the gaps in the salaries offered for employees persisting over the whole period.

The largest discrepancies among the state clusters of the European Union are, probably, in terms of private sector investments in research and development. As in the case of innovation 
Figure 4 - Discrepancies in terms of per capita business R\&D expenditure by group of countries in the EU.

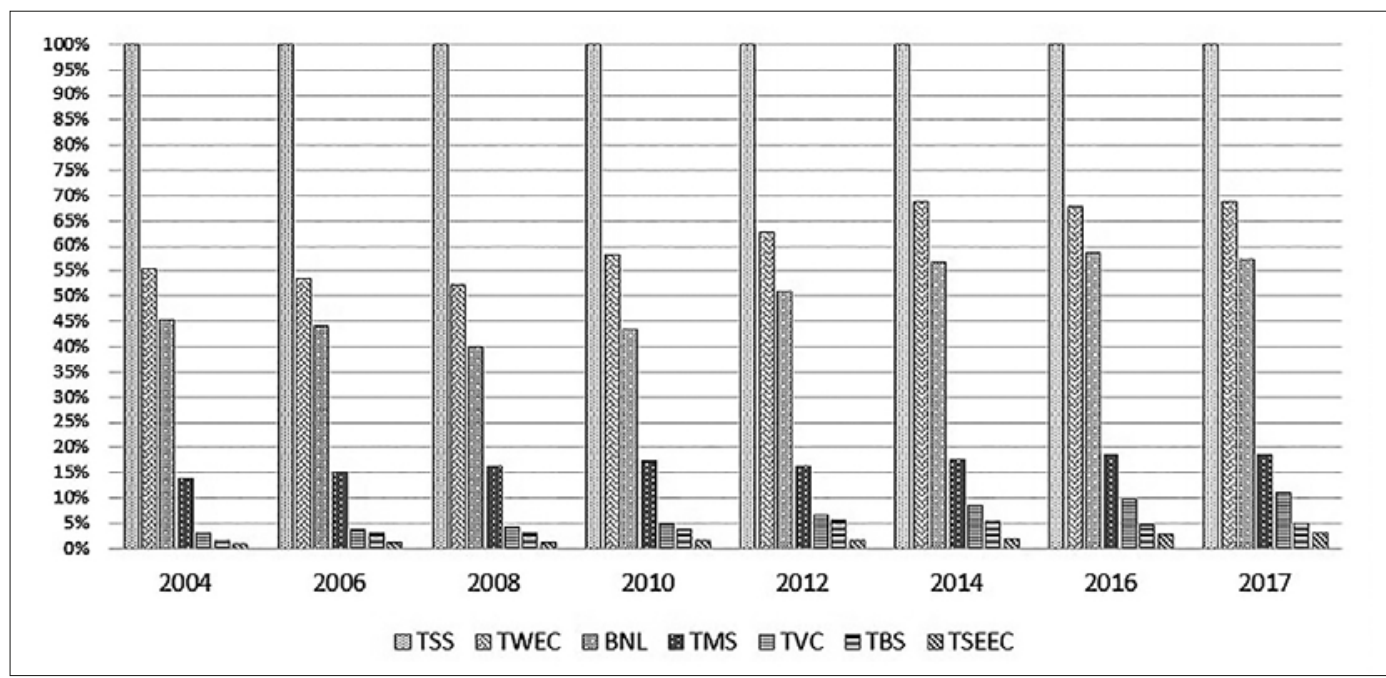

Source: Eurostat, indicator's code [rd_e_gerdtot].

output, the Scandinavian States register the highest performance, followed by the TWEC and BNL groups. The weakest countries in terms of business R\&D spending are TSEEC, TBS and TMS. It can be noticed that the differences between leading regions slightly diminish while the gaps between the leaders and lagging economies remain rather unchanged. This situation underlines the idea that the entrepreneurial environment in the European Union is highly heterogeneous, these differences tending to persist over the whole period. The business sector in less performant regions seem to be trapped since it cannot efficiently develop. For instance, the private sector in the South East European region invests in R\&D much less as compared to Scandinavian States, or, to be more specific, it matches only $3.03 \%$ of the innovation investments which are made in the Northern part of the European Union. It can be noticed that the innovation investment of the private sector in the Eastern Europe, and in part, in the Mediterranean region are stagnating, the reached levels being modest or weak as compared to more developed regions of the community.

As it can be observed in Table 2, the BNL group of countries have the most balanced financial policies in the European Union, these states having the most favourable international investments positions. These states are followed by the Western EU cluster and the Scandinavian States. More modest positive results are shown by the Mediterranean, Baltic and Visegrad regions. This indicator shows the crediting abilities of regions, the wealthiest and economically strong country clusters having the greatest financial potential. The only European group of countries which register negative investments positions are the South East European region, the situation which marks their weaker ability to provide investments on the international market. It should be underlined that TMS, TBS, TVC clusters managed to significantly improve their financial performance, moving from the category of debtors to creditors.

Based on the information provided in the Figure 5 , it can be underlined that the performance of EU's macro-regions in terms of gross fixed capital formation per capita is characterised by consistent variations. The leading group in this regard are the Scandinavian States, followed by Benelux and the Western European countries. At the same time, the least performant country clusters are the South Eastern part of the community, the Visegrad group and the Baltic States. The results of the Mediterranean countries are somewhere in the middle, neverthe- 
Table 2 - International Investment Position, percentage of gross domestic product (GDP).

\begin{tabular}{|l|r|r|r|r|r|r|r|r|r|}
\hline & 2004 & 2006 & 2008 & 2010 & 2012 & 2014 & 2015 & 2016 & 2017 \\
\hline BNL & 6.01 & 6.32 & 2.72 & 4.98 & 6.12 & 4.79 & 3.45 & 4.67 & 6.60 \\
\hline TWEC & 2.63 & 3.14 & 2.72 & 2.82 & 3.24 & 3.47 & 4.43 & 4.03 & 4.22 \\
\hline TSS & 4.67 & 5.67 & 4.95 & 4.87 & 3.70 & 4.04 & 4.00 & 3.73 & 3.48 \\
\hline TMS & -3.54 & -5.81 & -7.06 & -4.69 & -0.67 & 1.23 & 1.14 & 1.94 & 1.96 \\
\hline TBS & -9.78 & -14.89 & -12.19 & 0.42 & -2.21 & 1.14 & -0.89 & 0.54 & 1.30 \\
\hline TVC & -6.07 & -4.69 & -5.95 & -4.16 & -2.12 & -0.89 & -0.05 & 0.73 & 0.63 \\
\hline TSEEC & -7.79 & -12.14 & -14.22 & -4.20 & -3.76 & -0.19 & -0.88 & -0.85 & -0.62 \\
\hline
\end{tabular}

Source: Eurostat, indicator's code [bop_gdp6_q].

less, the registered dynamics are unfavourable since the group's performance considerably decreased as compared to the leading economies. Lower levels of gross fixed capital formation demonstrate that less advanced economies are not investing sufficient funding in the renewal of the capital basis.

One of the indicators reflecting economic competitiveness is per capita exports. The leading exporters in the European Union are the Benelux countries, followed by the Scandinavian and Western European countries. The most modest performance in terms of per capita exports is characteristic for the South Eastern part of the EU, as well as the Mediterranean countries, the Baltic and the Visegrad States. The exports of the least competitive group match only $11.11 \%$ of the leading countries cluster. The export discrepancies have not diminished over the researched period and tend to persist, the situation which remarks the heterogeneity of single market's competitiveness.

Based on the information provided in the Figure 7 , it can be observed that the performance gaps in the area of energy efficiency among the countries groups is less evident as compared to other indicators, yet, it can be clearly differentiated between the "old" and "new" European member states. The leading countries in this regard are the Scandinavian States, while the least competitive are the South East European countries which make only $45.53 \%$ of the energy efficiency registered in the Northern EU. It should be observed that the differences in these

Figure 5 - Discrepancies in terms of per capita gross fixed capital formation per capita by group of countries in the EU.

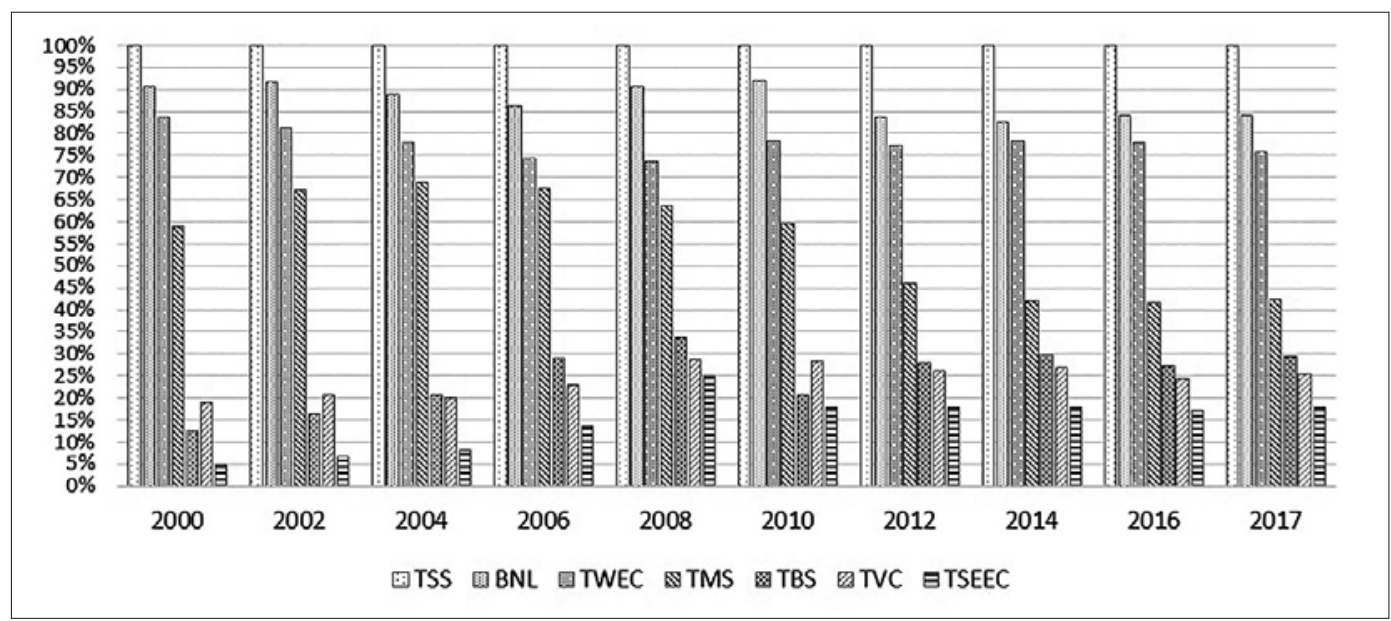

Source: Eurostat, indicator's code [nama_10_gdp]. 
Figure 6 - Discrepancies in terms of per capita exports by group of countries in the EU.

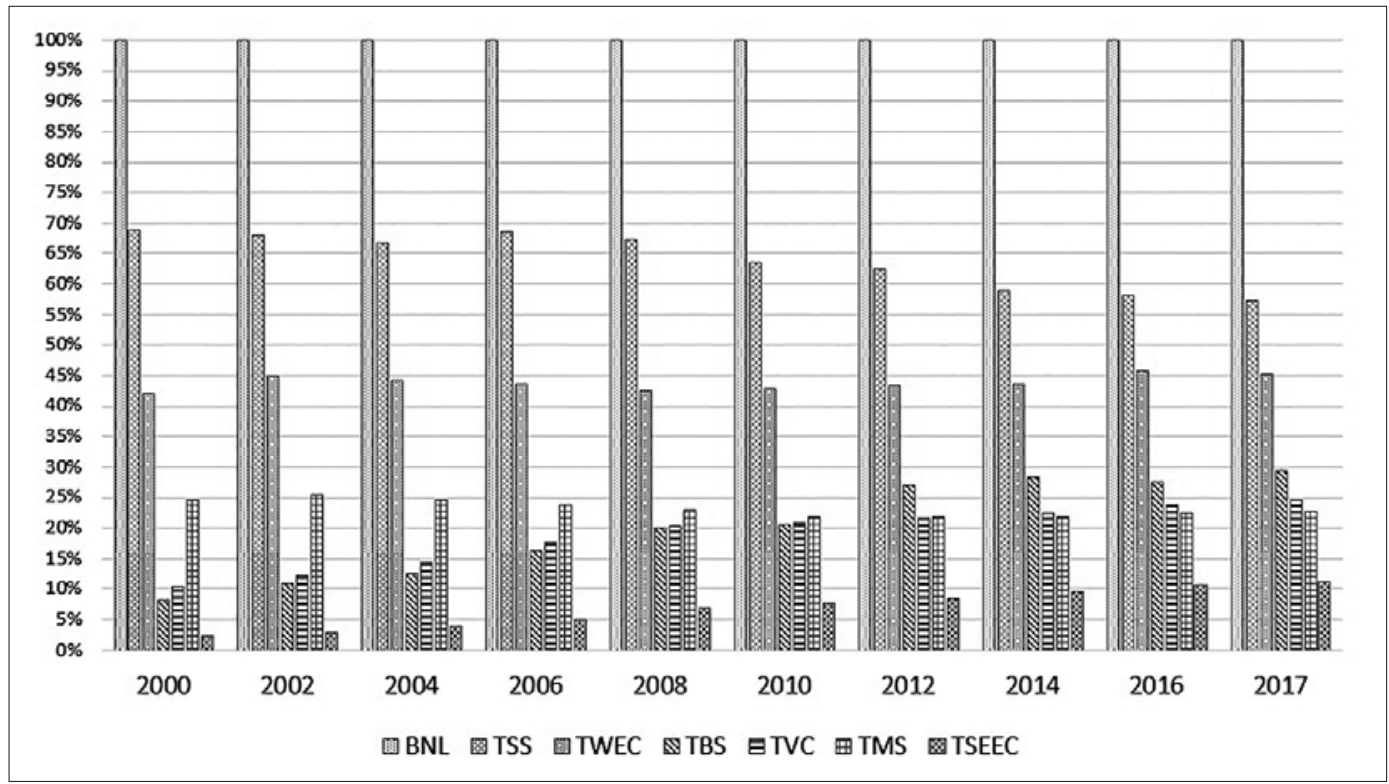

Source: Eurostat, indicator's code [nama_10_gdp].

Figure 7 - Discrepancies in terms of per kilogram of oil equivalent energy efficiency by group of countries in the EU.

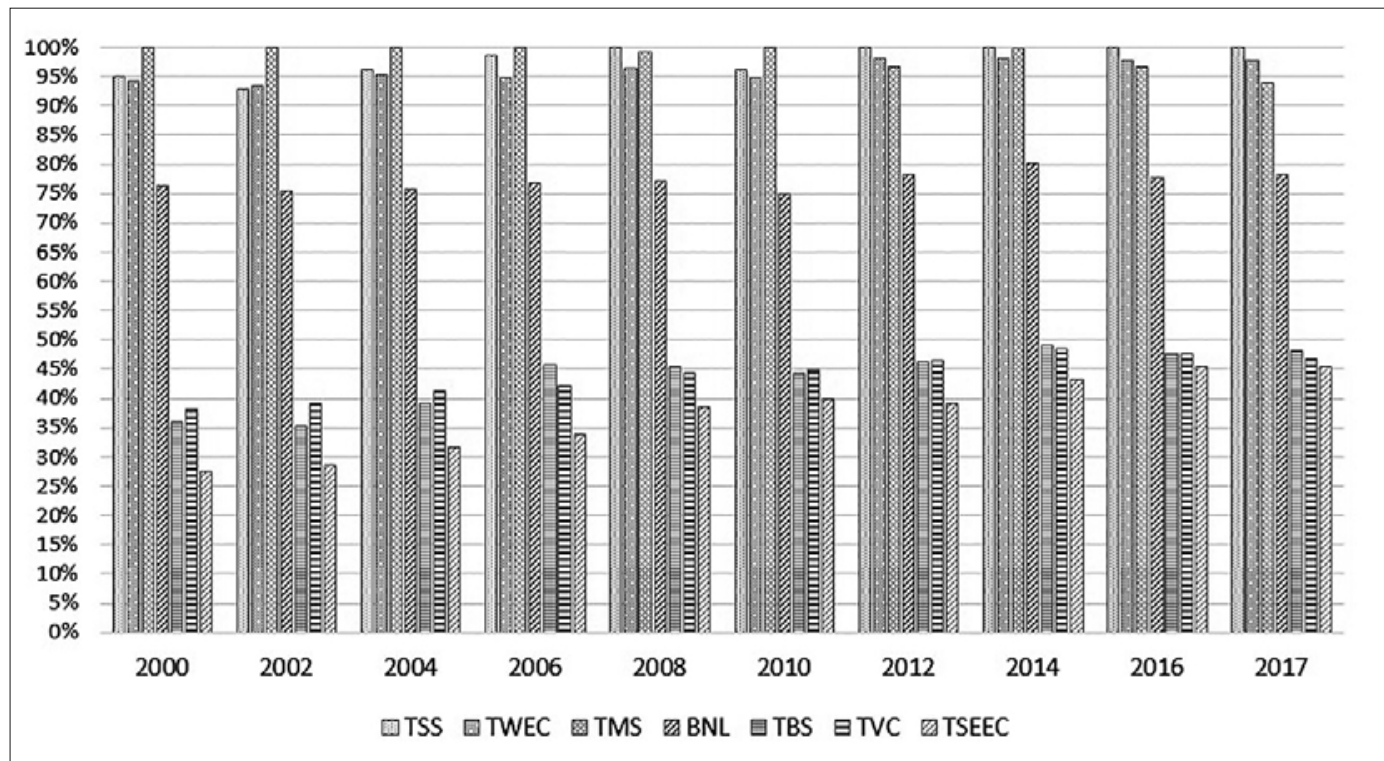

Source: Eurostat, indicator's code [sdg_07_30].

areas have slightly diminished, thus, overall performance of the community increasing. The Eastern European clusters i.e. TBS, TVC and TSEEC register more or less similar performances, this situation being determined by the similar economic structure inherited during the communism.

The countries cluster which is the most affected by unemployment in the European Union is the Mediterranean region (Table 3). High lev- 
Table 3 - Unemployment, percentage of active population.

\begin{tabular}{|l|r|r|r|r|r|r|r|r|r|c|}
\hline & 2000 & 2002 & 2004 & 2006 & 2008 & 2010 & 2012 & 2014 & 2016 & 2017 \\
\hline TMS & 10.44 & 9.63 & 9.35 & 7.85 & 8.52 & 13.00 & 17.13 & 18.03 & 15.29 & 13.80 \\
\hline TBS & 15.36 & 12.86 & 11.00 & 6.21 & 6.35 & 18.13 & 13.23 & 10.07 & 8.23 & 7.35 \\
\hline TSS & 6.35 & 6.44 & 7.25 & 6.38 & 5.49 & 8.25 & 7.78 & 7.76 & 7.21 & 6.93 \\
\hline TWEC & 7.88 & 7.99 & 9.38 & 9.18 & 7.21 & 8.02 & 7.43 & 7.36 & 6.74 & 6.23 \\
\hline BNL & 4.91 & 5.15 & 6.73 & 6.27 & 5.00 & 6.27 & 6.49 & 7.80 & 6.70 & 5.77 \\
\hline TSEEC & 9.94 & 10.93 & 9.09 & 7.68 & 5.60 & 7.88 & 8.26 & 8.02 & 6.35 & 5.25 \\
\hline TVC & 13.62 & 15.58 & 15.25 & 11.76 & 6.98 & 9.95 & 10.07 & 8.68 & 5.97 & 4.74 \\
\hline
\end{tabular}

Source: Eurostat, indicator's code [une_rt_a].

els of unemployment are registered during the whole period of time, yet, the dynamics deteriorated more in the last few years. This situation marks the serious economic challenges which this group of states is presently meeting. Opposite evolution can be remarked in the Baltic States, unemployment gradually decreasing, present levels being slightly overpassing the normal rate of unemployment. The same dynamics can be underlined also for the Visegrad States. On overall, the present rate of unemployment is threatening economic security of the Mediterranean countries affecting the stability of the whole community.

The correlation coefficients between the indicators were calculated to find out the linear association between the variables. As it can be observed, the vast majority of coefficients are strong and positive (Table 4). In order to exclude the possibility that these variables are associated due to coincidence, it was performed the Kaiser-Meyer-Olkin (KMO) Test for sampling adequacy. It was reached the value of 0.80 which marks that the data sample is adequate, factor analysis is useful with the data. Afterwards, it was calculated the Bartlett's test of sphericity reaching 0.001 indicating that variables are unrelated and therefore suitable for analysis, therefore, it is concluded that the analysis performed is significant and the relationships identified are meaningful.

Table 5 provides information regarding the interdependence between the selected indicators at the level of the European Union. In the

Table 4 - Pearson's correlation coefficient between the selected indicators. ${ }^{1}$

\begin{tabular}{|l|c|c|c|c|c|c|c|c|c|}
\hline & $B R D$ & $R P$ & $C E$ & $E D$ & $G F C F$ & $E X$ & $P A P$ & $E E$ & UNEM \\
\hline BRD & 1.00 & & & & & & & & \\
\hline RP & 0.56 & 1.00 & & & & & & & \\
\hline CE & 0.90 & 0.84 & 1.00 & & & & & & \\
\hline ED & 0.68 & 0.67 & 0.75 & 1.00 & & & & & \\
\hline GFCF & 0.92 & 0.76 & 0.98 & 0.69 & 1.00 & & & & \\
\hline EX & 0.69 & 0.80 & 0.83 & 0.71 & 0.82 & 1.00 & & & \\
\hline PAP & 0.96 & 0.64 & 0.93 & 0.72 & 0.93 & 0.73 & 1.00 & & \\
\hline EE & 0.76 & 0.74 & 0.87 & 0.61 & 0.83 & 0.51 & 0.75 & 1.00 & \\
\hline UNEM & -0.34 & -0.04 & -0.24 & -0.09 & -0.36 & -0.38 & -0.36 & 0.02 & 1.00 \\
\hline
\end{tabular}

Source: Own calculations.

1 BRD-Business R\&D expenditure; RP-Resource productivity; CE-Compensation of employees; ED-External Debt; GFCF-Gross fixed capital formation; EX-Exports; PAP-Patent applications; EE-Energy efficiency; UNEM-Unemployment. 
table there are presented the parameters and intercepts. In cells marked with "non", the independent variable was not included in the model and respective parameter was not calculated due to high values of $p$ coefficient. As it can be remarked, the coefficient of determination is relatively high for all linear regressions, except for unemployment, where it is 0.55 , a smaller value as compared to the rest of cases.

As it can be observed, patent applications (PAP) in the European Union interact with all independent variables. Patent applications is one of the outputs of innovation activity it being directly dependent on business research and development expenditures (BRD), the more entrepreneurs spend on innovation the higher is the output (Table 5). At the same time, it can be mentioned the direct link with resource productivity (RP) and compensation of employees (CE). Raising the level of productivity permits earning higher profits leading to additional funding which may be invested into innovation. At the same time, higher salaries offered for employees stimulate their involvement in the work processes and labour commitment, including in the R\&D related activities, the fact which leads to larger innovation output and productivity. The positive dependence on external debt marks the favourable impact of crediting on financing innovation expenses, incurring debt being one of the sources to support firms in this area. Patent application is also positively interdependent with gross capital formation, the situation explained through the auspicious effect of capital intensity on productivity and, therefore, freeing additional funding for R\&D. Innovation output is directly related to all independent variables except exports, energy efficiency and unemployment. This situation can be explained through the following ideas and namely: decrease of export or energy efficiency leads to growth in terms of per capita patent applications. Innovation activity is supposed to compensate the decline of competitiveness in these areas, thus, the private and public sectors tend to concentrate more resources and investments into innovation to cover the registered decline, the factors leading to growth of the respective output. At the same time, raise in terms of unemployment removes part of the work force from the economic flows, situation characterising declining efficiency of business activities, and, consequently, fewer financing opportunities oriented towards strengthening innovation capacities of the firms.

Per capita exports are directly dependent on business research and development expenditures, resources productivity, employees' compensation, external debt, and gross capital formation. This situation underlines the idea that stimulation of either of the mentioned independent variables through different policy measures will strengthen export potential. In particular, more business research and development investments are made by entrepreneurs the higher is the level of activity of the private sector resulting in greater presence on the markets, including the foreign ones (Table 5). Resources productivity growth makes European exports more attractive for consumers, these being more competitive on foreign destinations. Increase in terms of employees' compensation leads directly to output and productivity growth since workers have larger motivation and improved labour satisfaction. Raise of external debt level is a source of business activities financing which offers the private sector additional funding to expand activities and, therefore, compete for foreign markets. At the same time, gross capital formation growth enhances the economic potential through improved infrastructure, productive units and equipment, indispensable conditions for more prominent export presence. Another interesting finding is related to indirect interdependence between exports and patent applications, which may seem an output of business research and development. Nevertheless, unlike patent applications, business research and development as an independent variable not necessarily presupposes obtaining a patent, business innovation may also include designing of new processes, trademarks, industrial secrets, as well as it may also cover funding allocated to reaching new markets and creation of new supply chains. Therefore, in order to be competitive in exports, it is not necessarily to invest in projects which will have as a final point a patent. However, it should be invested into other activities linked to research and development providing a competitive advantage 
in terms of products and services' improvements. Explaining the indirect interdependence between exports and energy efficiency may be a little bit more complex. The negative interdependence may be caused by the restrictive impact of additional fuel taxes. It is known that the prices for energy resources in the European Union are higher as compared to other regions of the World including the USA, China and India. Raising fuel excises will immediately lead to a further increase in terms of energy prices. Higher price determines the business sector to optimise their expenses related to energy consumption, the factor leading to growth in terms of energy efficiency, however, higher energy prices make European products more expensive on external markets. Moreover, high prices for energy may lead to less active and present business, thus, European exports will concentrate on directions with higher income, factors which will restrict European companies from entering less actively the markets with less income. In this way, an apparent benefit for the economy i.e. the increase of energy efficiency may determine decrease of competitiveness of European exports.

Business research and development expenditures at the level of the European Union are directly dependent on patent application i.e. innovation output, the fact showing the clear interdependence between investments and expected results (Table 5). Thus, the higher is the innovation output the more the private sector allocates funding, this fact being determined by the willingness of the businesses to keep up with competition. At the same time, it can be noticed that R\&D investments are positively related to exports. Thus, growing exports will drive innovation activities since the private sector is willing to keep the positions on the foreign markets or improve them depending on the interests which are followed. Simultaneously, energy efficiency is directly influencing business R\&D activity, unlike in the case of patent applications. In the conditions of expensive energy supplies, this situation is explained by the efforts of the entrepreneurial environment to optimise energy resources use. Therefore, in order to remain in business, firms will counterbalance price growth with optimisation of processes and activities requiring energy use, the fact demanding additional funding, thus, growth of energy efficiency leads to higher expenditures of the private sector for R\&D activities. It is harder to explain how growth in unemployment stimulates these investments. A potential explanation for this relation is conditioned by the effect of unemployment on the labour market, since the growth diminish the business expenses related to salaries as the supply of labour is larger. Therefore, business environment are freeing parts of the funding dedicated for salaries directing them to improving their activities i.e. through expanding on new markets or protecting the existing positions. Business $\mathrm{R} \& \mathrm{D}$ expenditures are indirectly linked to resources productivity and external debt. The first is explained by the inverse effect of resources productivity the decrease of which motivates the business sector to allocate additional funding to $R \& D$ to search for means of improving the dynamics, while growth, on contrary, is a sign of relative stability of business competitiveness, reducing, therefore, the need for these investments. External debt is also inversely linked to business R\&D. Incurring credits is linked to the shortage of funding and is made to compensate it. Therefore, growth in terms of debt marks the weak ability of business sector to operate normally. Moreover, growing debt increases the burden which in turn minimise the quantity of available investment funding.

Resources productivity is directly connected to patent applications the fact which is explained by the beneficial effect of innovation output and its implementation in the economy resulting in improved productivity margins (Table 5). At the same time, it can be mentioned that it is also directly dependent on exports. Thus, improving export capacities will increase resources productivity, this favourable effect being a consequence of enhanced international competition which determines the exports to be efficient. Another indicator directly determining resources productivity is energy efficiency. Growth of energy efficiency leads to the increase of resources productivity since entrepreneurs in the seeking of optimal use of energy supplies improves overall efficiency of the business processes within the enterprises. Finally, RP is directly conditioned 
Table 5 - Linear regression analysis between the selected indicators to find the existing relations and influence, confidence 0.95, P-value $<0.05$, Significance F $<0.05$.

\begin{tabular}{|c|c|c|c|c|c|c|c|c|c|c|}
\hline \multirow{3}{*}{\multicolumn{2}{|c|}{$\begin{array}{l}\text { Coefficient of } \\
\text { determination }\end{array}$}} & \multicolumn{9}{|c|}{ Dependent variables } \\
\hline & & \multirow{2}{*}{$\begin{array}{l}P A P \\
0.98 \\
\end{array}$} & \multirow{2}{*}{$\begin{array}{c}E X \\
0.97 \\
\end{array}$} & \multirow{2}{*}{$\begin{array}{l}B R D \\
0.97 \\
\end{array}$} & \multirow{2}{*}{$\begin{array}{c}R P \\
0.95 \\
\end{array}$} & \multirow{2}{*}{$\begin{array}{c}C E \\
0.99 \\
\end{array}$} & \multirow{2}{*}{$\begin{array}{l}E D \\
0.78 \\
\end{array}$} & \multirow{2}{*}{$\begin{array}{c}G F C F \\
0.99 \\
\end{array}$} & \multirow{2}{*}{$\begin{array}{c}E E \\
0.98 \\
\end{array}$} & \multirow{2}{*}{$\begin{array}{c}\text { UNEM } \\
0.55 \\
\end{array}$} \\
\hline & & & & & & & & & & \\
\hline \multirow{10}{*}{ 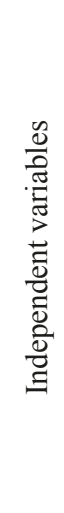 } & PAP & $“="$ & -79.88 & 2.29 & 0.0041 & 43.81 & 0.08 & 4.19 & -0.02 & -0.04 \\
\hline & Intercept & 84.28 & 9573.61 & -232.97 & -0.73 & -4094.42 & -11.56 & non & 2.29 & 10.00 \\
\hline & $\mathrm{EX}$ & -0.01 & $"="$ & 0.013 & 0.0001 & 0.28 & 0.001 & 0.11 & -0.0002 & -0.0002 \\
\hline & BRD & 0.17 & 12.58 & $"="$ & -0.0027 & non & -0.01 & non & 0.0029 & 0.006 \\
\hline & RP & 19.08 & 3824.20 & -167.38 & $"="$ & 1867.89 & -3.95 & -638.51 & 0.69 & non \\
\hline & $\mathrm{CE}$ & 0.008 & 0.60 & non & 0.0001 & $"="$ & non & 0.11 & 0.0001 & 0.0007 \\
\hline & ED & 2.55 & 351.27 & -2.85 & -0.0231 & non & $"="$ & -67.67 & 0.0674 & non \\
\hline & GFCF & 0.01 & 2.47 & non & -0.0003 & 1.15 & -0.0044 & $"="$ & 0.0004 & -0.0027 \\
\hline & $\mathrm{EE}$ & -31.22 & -4156.94 & 56.62 & 0.2648 & 1602.32 & 3.68 & 414.23 & $"="$ & non \\
\hline & UNEM & -1.65 & non & 5.87 & non & 124.57 & non & -61.24 & non & $"="$ \\
\hline
\end{tabular}

Source: Own calculations.

by compensation of employees, thus, raising salaries will improve overall use of resources, these beneficial effects being determined by growth in terms of labour efficiency fostered by more favourable labour satisfaction. Simultaneously, it should be mentioned that resources productivity is negatively related to business research and development, external debt and gross fixed capital formation. The first situation is explained by the fact that not all business expenditures on research and development are justified and have a final outcome. In these conditions, by simply raising the level of expenditures it will not be improved productivity since much of the spending is not economically justified. Growth of this spending should be determined by the necessities of the market and not artificial initiatives as, in the last case, the investments will not bring additional efficiency. In the second situation, incurring debt leads to additional spending on the premium or rates, the larger is the burden the higher is the pressure on the business. Costs of crediting are expenses which negatively affect the productivity. Finally, gross capital formation not always include equipment which will directly improve the productivity margins. It also covers a wide set of investment positions which not necessarily advance the efficiency of firms' activities, yet serve as a potential strategic position for the future. One of the examples could serve as acquisition of buildings or land which is not directly used in productive activities. These costs are usually high and are intended for the future use of benefit.

Compensation of employees is directly dependent on innovation output i.e. patent applications. This fact is not surprising since innovation leads to the increase of productivity which in turn raise the possibilities of firms to offer higher salaries and remuneration (Table 5). The same situation could be observed in the case of exports, by selling products and services abroad, firms enlarge their market coverage capacities, thus, being able to reach a higher number of customers. Positive dependence is remarked for gross capital formation, namely, capital offers the opportunity to develop business activities and grow output strength. Both resources productivity and energy efficiency have the highest positive impact on salaries of employees. Accordingly, productivity, as a general driver, can be regarded as the main factor affecting income of workers. Finally, it can be noticed direct interdependence between compensation of employees and unemployment. This fact is surprising since it, somehow, opposes the gen- 
eral rules of the market, nevertheless, the situation is particular for the European Union and, therefore, can be explained through the impact of social protection mechanisms and policies reflected mainly by unemployment insurance. High unemployment rates underline large public expenditures on unemployment insurance. These compete market mechanisms, thus, high rates not necessarily meaning larger labour supply and, therefore, lower compensation. Rather, high unemployment rates underline the fact that people would prefer living on unemployment insurance, than going to work on the present salary level. In this case, the business sector is obliged to considerably raise remuneration as to motivate persons to join labour market. Namely, a mechanism which is apparently aimed to protect people in need demotivates employment and stimulates "dawdling", similar situation characteristic for the bees' society.

At the same time, external debt of European countries is directly dependent on innovation output. Accordingly, it can be underlined that high level of patent applications demands funding to implement innovation into economic processes. One of the sources which can be considered when implementing innovation is debt (Table 5). Unlike patent application, business research and development expenditures are inversely connected to external debt. In this case, the exemplification is linked to the debt burden, hence, the higher is its level the lower financial resources the business sector will have disposable to invest. The same connection is also seen for debt and resources productivity and gross fixed capital formation. In this regard, it can be underlined that debt burden and its growth diminish investments into developing the capital base of the economy, while interest payments reduce level of resources productivity. Growth of the debt is a sign of financial resources shortage, trying to cover this deficit with credits increase pressure on business activities due to interests' payments. Simultaneously, it can be noticed a direct link between debt and export as well as energy efficiency. In the first case, i.e. export, debt is regarded as a source of financing export linked activities and production costs, while, in the second case, i.e. energy efficiency, growth of debt burden determines economies to optimise energy costs, the situation leading to higher efficiency, yet, relatively questionable effectiveness.

In the case of gross fixed capital formation, it can be mentioned that it is directly dependent on patent applications. Innovation output and its implementation in the economy is associated with important expenditures related to purchasing physical assets necessary to introduce inventions into commercial flows (Table 5). The same relation can be observed for exports, namely, growing exports are supported by additional production which demands fixed capital investments to broaden business capacities. Simultaneously, energy efficiency directly influences the evolution of gross fixed capital formation, relation explained through the availability of financial resources, higher energy efficiency leading to larger disposable income which can be invested in strengthening the capital basis of the business. At the same time, it can be observed that there exists a negative dependence on resources productivity, the fact which is determined by the necessity of business to increase resources productivity when it is decreasing through additional investments into fixed capital. When the level of productivity is relatively high and acceptable, businesses find not necessity to further invest into capital basis, therefore, the respective expenditures are low. There is a negative dependence of gross fixed capital on external debt, the fact determined by the negative impact of the debt burden on the strength of the business sector in terms of finance. Debt burden diminish firms' investments as these have less funding available to increase capital basis. Also, the same relation can be observed in the case of unemployment. Decrease of unemployment is linked to the expansion of business production capacities since more people are employed and they need fixed capital to efficiently perform their tasks. In case unemployment rate grows, it means that the business sector and the economy as a whole is requiring less workforce, thus, there is no need for the firms to invest funding to strengthen the capital basis.

Energy efficiency is inversely dependent on innovation output. This relationship is surprising and a potential explanation for it is linked 
to the specific nature of energy efficiency arising from government energy policies influencing its prices. Patents applications as innovation outputs require important investments and entail consistent costs, including energy ones, which, depending on the essence of business activity, may not always be justified (Table 5). Thus, innovation almost always implies energy costs, at different stage of invention development, yet, its application within the economy may not bring benefits to foster energy efficiency. The same relation is characteristic for exports, a business activity which is relatively costly and involves many variables oriented towards increasing profits or market presence, factors which not necessarily imply minimal costs. Unlike patent applications, business research and development expenditures have direct relation to energy efficiency. This fact underlines the idea that, business R\&D are not necessarily oriented towards reaching a patent or invention, these efforts may lead to designing, for instance, a new product, process or a marketing approach. Business R\&D spending may seek optimisation including of the costs related to energy consumption, therefore, there is a direct link between the variables. Simultaneously, it can be marked the direct interconnection with resources productivity, increase of which leads to more efficiency of costs. Energy efficiency is directly linked to compensation of employees, growth of salaries being a strong motivation for workers to increase return and production yield. External debt burden is directly influencing energy efficiency, this situation is determined by the necessity of business sector to optimise their costs, including energy ones, direction conditioned by debt pressure. Finally, it can be underlined that there is a direct dependence of energy efficiency on gross fixed capital formation, capital being one of the essential components of efficiency including in the energy area, strengthening business capital basis offering a strategic cost advantage.

The coefficient of determination between unemployment and the independent variables is weaker as compared to the rest of cases, 0.55 . Nevertheless, it can be observed that unemployment is inversely related to patent applications. Accordingly, it can be remarked that stimulation of innovation output fosters employment within the economy (Table 5). The same observation can be made for exports, the favourably dynamics of it being a factor promoting jobs creation. A similar relation is characteristic for gross capital formation, capital tending to rather create workplaces. Simultaneously, it can be noticed that business research and development expenditures is directly interconnected to unemployment, the situation which is explained through the tendency of businesses to optimise activities through searching for new ways of improving positions. These improvements may cause reduction of employment as optimised processes and activities require less workforce. It is surprising to find out that unemployment is directly influenced by level of employees' compensation, it may seem that the vice-versa case is more suitable. Nevertheless, this "paradox" is explained through the willingness of business sector to retain employees considering the following conditions: high governmental unemployment payments, competition for qualified workforce and an important number of unqualified labours joining joblessness category.

\section{Conclusions}

Economic convergence in the European Union has certainly improved in the post-crisis years. This progress is an achievement of European development policies which have been oriented towards strengthening the economic potential of the less developed member countries. Still, the extent to which development discrepancies diminished is not sufficient to increase the congruence of the single market, it remaining disperse in terms of economic attractiveness and growth potential. It be noticed clear differences in terms of economic performance and competitiveness between the countries of the community. The countries are particularly affected by varying income levels and competitiveness not only inside the European Union, but also, in the Euro Area. The problem is even more acute considering the fact that the capital regions tend to concentrate much of the economic activity. This phenomenon is distinctive for the less developed European states mainly located in the East and South. 
Thus, for instance, economic performance in a region of the South East European Union which is located far from the centre will be much less prominent as compared to similar regions in the West and North. The European Union understood this strategic weakness which may cause drop of overall development perspective. This threat arises as a result of heterogeneous entrepreneurial strength determined by the differences in terms economic opportunities characteristic for each state.

Accordingly, the present paper accepts the research hypothesis specifying that discrepancies in terms of entrepreneurial performance between the countries of the European Union reduce the level of economic security and growth potential of the community. The entrepreneurial performance in the European Union is highly heterogeneous, the North and West reporting increased performance while the East and South are stagnating. This situation creates development turbulences which reduce the congruence of the single market and diminish its overall growth potential. In this situation, both the developed and developing macro-regions of the European Union are in disadvantage, the first being unable to further growth due to the reduced consumption capacities of the second, and respectively, the second is not able to progress without consistent investments and efficient institutions. The dynamics of discrepancies are not favourable, in the period of 2000-2017, little progress being made in the area of raising the entrepreneurial performance cohesion. One of the factors which reduce the growth potential of the Union is the persisting differences in the single market, some countries succeeding to build strong entrepreneurial environment, while others are not able to efficiently eradicate corruption, reinforce institutions, situation which motivate further development lagging. This factor, if not properly approached, will reduce the growth potential, and therefore, the level of economic security of the whole Union.

The problem is in the present institutional arrangements and empowerments of the EU. Consequently, the community needs to consolidate central authorities responsible for the efficiency of the single market. This fact will permit to avoid regulation differences among the member countries in the business field. This step is an evolutionary step in the process of European integration. Delegating more authority to central European government allows smoothing business climate, and therefore, determines higher cohesion. In this case, the single market will strengthen its congruence, a determinant factor to boost business performance and, respectively, enhance economic security.

\section{References}

Anagnostou A., Kallioras D., Kollias C., 2016. Governance convergence among the EU28?. Social Indicators Research, 129(1): 133-146.

Andersen T.M., Bertola G., Driffill J., Fuest C., James H., Sturm J.E., Uroševic B., 2018. It's OK to Be Different: Policy Coordination and Economic Convergence. EEAG Report on the European Economy, Munich: CESifo, pp. 64-82.

Arvanitidis P., Kollias C., Messis P., 2016. Asymmetric convergence in globalization? Findings from a disaggregated analysis. Managing Global Transitions, 14(2): 117.

Belostecinic G., Sakovici V., Moiseenco E., 2011. Securitatea economică a statului: teorie, metodologie, practică, Chisinau: Academia de Studii Economice a Moldovei (ASEM), p. 127. ISBN 9789975-75-574-0.

Bieling H.J., Jäger J., Ryner M., 2016. Regulation theory and the political economy of the European Union. JCMS: Journal of Common Market Studies, 54(1): 53-69.

Blanco F.A., Delgado F.J., Presno M.J., 2018. $R \& D$ Expenditure in the EU: Convergence or Divergence?. Working Papers. Collection B: Regional and sectoral economics 1804. Universidade de Vigo, GEN-Governance and Economics research Network.

Borsi M.T., Metiu N., 2015. The evolution of economic convergence in the European Union. Empirical Economics, 48(2): 657-681.

Ćetković S., Buzogány A., 2016. Varieties of capitalism and clean energy transitions in the European Union: When renewable energy hits different economic logics. Climate Policy, 16(5): 642-657.

Chen Z., 2016. China, the European Union and the fragile world order. JCMS: Journal of Common Market Studies, 54(4): 775-792.

Ciocanel A.B., Pavelescu F.M., 2015. Innovation and competitiveness in European context. Procedia Economics and Finance, 32: 728-737. 
Combes P.P., Overman H.G., 2004. The spatial distribution of economic activities in the European Union. In: Henderson J.V., Thisse J.F. (eds.), Handbook of urban and regional economics, vol. 4. Amsterdam: Elsevier, pp. 2845-2909.

Dall'Erba S., Fang F., 2017. Meta-analysis of the impact of European Union Structural Funds on regional growth. Regional Studies, 51(6): 822-832.

Dimitrios A., Helen L., Mike T., 2016. Determinants of non-performing loans: Evidence from Euro-area countries. Finance research letters, 18: 116-119.

Dragneva R., Wolczuk K., 2015. European Union emulation in the Design of Integration. In: Lane D., Samokhvalov V. (eds.), The Eurasian Project and Europe. London: Palgrave Macmillan, pp. 135-152.

Forte A., Peiró-Palomino J., Tortosa-Ausina E., 2015. Does social capital matter for European regional growth?. European Economic Review, 77: 47-64.

Goecke H., Hüther M., 2016. Regional convergence in Europe. Intereconomics, 51(3), 165-171.

Guild E., Carrera S., Balzacq T., 2016. The changing dynamics of security in an enlarged European Union. In: Bigo D., Walker R.B.J. (eds.), Europe's 21st Century Challenge. London: Routledge, pp. 53-70.

Hallerberg M., Marzinotto B., Wolff G.B., 2018. Explaining the evolving role of national parliaments under the European Semester. Journal of European Public Policy, 25(2): 250-267.

Ignatov A., 2018. Regional Development Discrepancies in the Eastern European Union Analysed through the Prism of Growth Determinants. Global Economy Journal, 18(4): 1-18.

Ignatov A., 2019. Analysis of the dynamics of the European economic security in the conditions of a changing socio-economic environment. New Medit, 18(2), 15-38.

Kijek T., Matras-Bolibok A., 2018. Innovativeness of European regional space: convergence or divergence? Acta Scientiarum Polonorum. Oeconomia, 17(1):59-65.

Koenig N., Walter-Franke M., 2017. France and Germany: spearheading a European security and defence union?. Policy Paper, 202: 1-18.

Loewen B., Schulz S., 2019. Questioning the Convergence of Cohesion and Innovation Policies in Central and Eastern Europe. In: Lang T., Görmar F. (eds.), Regional and Local Development in Times of Polarisation. Singapore: Palgrave Macmillan, pp. 121-148.

Lopez-Bazo E., 2017. Growth and convergence across economies: the experience of the European regions.
In: Fingleton B., Eraydn A., Paci R. (eds.), Regional economic growth, SMEs and the wider Europe. London: Routledge, pp. 65-90.

Magone J., 2017. The new world architecture: the role of the European Union in the making of global governance. London: Routledge.

Okólski M., 2017. New migration movements in Central and Eastern Europe. In: Joly D. (ed.), International migration in the new millennium. London: Routledge, pp. 46-66.

Paci R., Pigliaru F., 2002. Technological Diffusion, Spatial Spillovers and Regional Convergence in Europe. In: Cuadrado-Roura J.R., Parellada M. (eds.), Regional Convergence in the European Union. Berlin, Springer, pp. 273-292.

Pegkas P., 2015. The impact of FDI on economic growth in Eurozone countries. The Journal of Economic Asymmetries, 12(2): 124-132.

Potužáková Z., Öhm J., 2018. R\&D investments, EPO patent applications and the economic heterogeneity within the EU. Review of Economic Perspectives, 18(2): 177-191.

Quah D.T., 1996. Empirics for economic growth and convergence. European economic review, 40(6): 1353-1375.

Rodríguez-Pose A., Tselios V., 2015. Toward inclusive growth: Is there regional convergence in social welfare?. International Regional Science Review, 38(1): 30-60.

Salvatore D., 2018. Mediterranean challenge: Inclusive growth and sustainable development. New Medit, 17(3): 3-8.

Siljak D., 2015. Real economic convergence in the European Union from 1995 to 2013. The Business \& Management Review, 6(4): 213-225.

Slomp H., 2017. European Governments and Labour Relations: Convergence or Divergence?. In: Goverde H. (ed.), Global and European Polity?: Organisations, Policies, Contexts. London: Routledge, pp. 105-117.

Szymańska A., Zalewska E., 2018. Towards the goals of the Europe 2020 strategy: Convergence or divergence of the European Union countries?. Comparative Economic Research, 21(1): 67-82.

Vella M., 2015. Economic Convergence in the European Union: How does Malta Fit in?. Review of European Studies, 7(3): 229-244.

Völlmecke D., Jindra B., Marek P., 2016. FDI, human capital and income convergence-Evidence for European regions. Economic Systems, 40(2): 288-307. 